\title{
Л.А. Латышева
}

Тихоокеанский институт географии ДВО РАН, г. Владивосток, Россия

\section{Влияние антропогенной трансформации лесной растительности на динамику содержания и состава гумуса в буроземах островных территорий юга Приморья}

\begin{abstract}
На примере острова Русский рассматривается динамика содержания и состава гумуса в буроземах, сформированных под растительными сообществами, находящимися на разной стадии антропогенной трансформачии. Выявлено, что в ходе антропогенной деградации лесной растительности в распространенных на острове буроземах активизируются процессы гумусообразования $u$ гумусонакопления и создаются предпосылки для развития иллювиально-гумусового прочесса почвообразования. Это проявляется в динамике внутрипрофильной дифференциации содержания в буроземах гумуса, его запасов (особенно в полуметровом слое) и качественного состава. Установлено, что от буроземов дубовыхлесовсоченьслаборазвитымтравяно-кустарниковымярусомкбуроземам изреженных дубовых лесов с хорошо развитым травяно-кустарниковым ярусом (преимущественно из лещины) в составе гумуса значительно возрастает доля черных гуминовых кислот, повышается подвижность их гумуса. При этом тип гумуса изменяется с гуматно-фульватного на фульватно-гуматный не только в верхней части почвенного профиля, но и в средней.
\end{abstract}

Ключевые слова: Южное Приморье; антропогенная деградация растительности; динамика; содержание гумуса; состав гумуса.

\section{Введение}

Территория прибрежно-островных экосистем юга Дальнего Востока по почвенно-географическому районированию России [1] относится к ЮжноСихотэ-Алинской горной провинции горных бурых лесных почв Восточной буроземной области с зональным буроземным типом почв.

В отличие от буроземов континентальной части юга Приморья, систематических исследований буроземов островных территорий практически не проводилось, в то время как почвообразование на рассматриваемой территории имеет ряд специфических и характерных черт. Островные экосистемы в наибольшей степени испытывают влияние океанического климата, обусловливающего пониженные значения среднемесячных температур, повышенное количество осадков и дней с туманами по сравнению с континентальной территорией юга Приморья. Отличительной чертой островного почвообразования является активное геохимическое воздействие моря на островные 
экосистемы в целом и их почвенный покров в частности. Оно выражается в дополнительном поступлении на территорию островов морских солей в процессе импульверизации их с поверхности моря, при конденсации влаги морских туманов, а также с атмосферными осадками [2].

Помимо этого, на условия почвообразования значительное влияние оказывает возрастающая с каждым годом антропогенная деградация лесной растительности островов (за счет рубок и пожаров) и замена ее на травянокустарниковые, травянистые растительные сообщества. Увеличение в напочвенном покрытии травяно-кустарниковой растительности способствует активизации биологического круговорота веществ и аккумуляции зольных элементов в почве и создает оптимальное сочетание температуры и влажности для жизнедеятельности разлагающих растительные остатки микроорганизмов [3].

Эти биотические и геохимические особенности формирования островных буроземов проявляются в динамике состава и свойств их почвенных растворов [2], физико-химических показателей, профильной миграции гумусовых веществ, и как следствие, содержании и составе их гумуса, обусловливая формирование морфологического разнообразия этих буроземов.

Выявление закономерностей в пространственной динамике содержания гумуса, его группового и фракционного состава в ряду островных буроземов растительных сообществ разной стадии антропогенной трансформации представляет несомненный научный интерес и является целью наших исследований.

\section{Материалы и методики исследований}

В качестве объекта исследования был выбран самый крупный остров в заливе Петра Великого (Японское море) - остров Русский. Географические

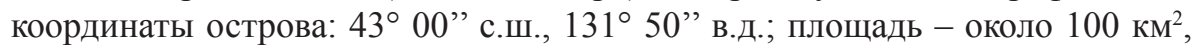
длина - 18 км, ширина - 13 км. От материковой части г. Владивостока его отделяет пролив Босфор Восточный шириной около 1 км. Характерным типом рельефа острова является низкогорье с абсолютными высотами до 300 м. Большая часть его сложена гранитами, гранодиоритами, диоритами, которые на западе острова сменяются песчаниками, алевролитами, аргиллитами, конгломератами. Климат резко выраженный муссонный, с высокими значениями годовых осадков, повышенной конденсацией влаги туманов, значительным числом дней с моросящими дождями [4].

Современная лесная растительность острова представлена вторичными дубовыми, дубово-липовыми лесами. Под воздействием систематических рубок и пожаров распространенные здесь в начале XIX в. хвойно-широколиственные леса трансформировались в дубовые и дубово-липовые, а последние - в изреженные дубняки с хорошо развитым травяно-кустарнико- 
вым ярусом, злаково-разнотравные растительные сообщества. Лесистость сократилась до 50\% [5, 6].

В почвенном покрове острова преобладают зональные для данной территории типы почв - буроземы типичные и буроземы темные [7-9]. Наряду с указанными типами буроземов были выделены ареалы специфических, не свойственных для континентальной части Приморья буроземов - буроземов темных иллювиально-гумусовых $[8,9]$, особенности формирования и распределения которых остаются пока недостаточно изученными.

Исследования динамики содержания и состава гумуса в островных буроземах проводились в ряду антропогенно трансформированных растительных сообществ, включающих: дубовые леса с очень слабо развитым травяно-кустарниковым ярусом $\rightarrow$ изреженные дубовые леса с примесью мелколиственных пород и сравнительно хорошо развитым травяно-кустарниковым ярусом $\rightarrow$ изреженные дубовые леса с хорошо развитым травянокустарниковым ярусом (преимущественно из лещины).

В отобранных образцах почв определяли гумус, его фракционно-групповой состав. Лабораторно-аналитические исследования выполнены с использованием общепринятых в почвоведении методов. Физико-химические показатели исследуемых буроземов были получены ранее и опубликованы [8].

\section{Результаты исследований и обсуждение}

Антропогенная деградация лесной растительности острова сопровождается изменением видового состава древостоя, уменьшением его сомкнутости и прогрессирующим развитием травянистого и кустарникового (преимущественно из лещины) ярусов. В результате усиливается влияние переноса солей на процессы почвообразования в распространенных здесь буроземах, повышается скорость биологического круговорота веществ, благодаря более богатому зольными элементами травянисто-кустарниковому опаду; как следствие, заметно увеличивается в составе обменных катионов ППК содержание кальция и магния как биогенного, так и морского происхождения.

Изменение условий формирования островных буроземов способствует активизации в их профиле процессов гумусообразования и гумусонакопления и создает предпосылки для развития иллювиально-гумусового процесса почвообразования. В зависимости от интенсивности проявления аккумулятивно-гумусового и иллювиально-гумусового процессов почвообразования в буроземах исследуемой территории выделены буроземы типичные, буроземы темные, буроземы темные иллювиально-гумусовые.

Буроземы типичные приурочены к дубовым, дубово-липовым лесам с очень слабо развитым травяно-кустарниковым ярусом и имеют следующее строение почвенного профиля: О-AY-ВМ-ВМС; разрез 27-02; заложен в центральной части острова. Верхняя часть склона восточной экспозиции, крутизной $7^{\circ}$. Абсолютная высота 105 м над ур. м. 
Под изреженными дубняками со сравнительно хорошо развитым травяно-кустарниковым ярусом описаны буроземы темные: O-AU-AUBM-BMC; разрез 21-02; заложен в северо-восточной части острова. Верхняя треть склона восточной экспозиции крутизной $10^{\circ}$. Абсолютная высота 70 м над ур. м.

Под изреженными дубняками с хорошо развитым кустарниковым ярусом и травянистым напочвенным покровом, а также под травянисто-кустарниковыми зарослями или травянистыми (преимущественно гмелинополынными) группировками формируются буроземы, выделенные нами как буроземы темные иллювиально-гумусовые: O-AU-AUBMhi-BMhi-BMC; разрез 23-02; заложен в северо-восточной части острова. Склон северо-восточной экспозиции крутизной $10^{\circ}$. Абсолютная высота 40 м над ур. м. Более подробное описание морфологических характеристик буроземов и участков, на которых они формируются, приведено в ряде публикаций $[8,9]$.

Специфика зольного состава и биологического круговорота, свойственная отдельным растительным видам и сообществам, отчетливо отражается в физико-химических показателях почв [10-12], обусловливая их динамику. В буроземах острова при увеличении в составе растительных сообществ, под которыми они формируются, травяно-кустарникового яруса отмечаются рост содержания в них гумуса $(11,02-14,05-14,92 \%)$, повышение степени насыщенности почв основаниями (82-87-95\%) на фоне уменьшения содержания обменного водорода $(6,18-6,20-1,87$ мг-экв/100 г) и величины гидролитической кислотности (12,32-11,87-7,61 мг-экв/100 г почвы) [8].

Буроземы типичные характеризуются более кислой реакцией среды, наиболее низким содержанием гумуса, обменных оснований и меньшими значениями степени насыщенности ими. Формирование гумусового профиля этих буроземов определяется аккумулятивно-гумусовым процессом почвообразования, а распределение по профилю характеризуется как регрессивно-аккумулятивное. Основная часть гумуса этих буроземов аккумулируется в верхней части профиля $(11,02 \%)$, а в горизонте ВМ содержание его резко падает до $2,00 \%$.

При антропогенной трансформации островных дубняков в изреженные дубняки со сравнительно хорошо развитым травяно-кустарниковым ярусом и в дубовые леса с хорошо развитым кустарниковым ярусом часто с преобладанием лещины изменяется морфологический облик гумусового профиля в буроземах острова: появляются темные гумусовые затеки в нижней части гумусового горизонта, увеличиваются интенсивность темно-серых цветов в его окраске и мощность. В формирующихся при этом буроземах темных и буроземах темных иллювиально-гумусовых мощность гумусовоаккумулятивного горизонта $\mathrm{A}+\mathrm{AB}$ возрастает до 38 и 53 см соответственно (по сравнению с 8 см в буроземах типичных) [8, 9]. Профильная дифференциация содержания гумуса в этих буроземах предопределяется развитием в них иллювиально-гумусового процесса почвообразования. Это наглядно иллюстрируется содержанием гумуса в этих буроземах как в верхней части 
профиля $(14,05-14,9 \%)$, так и в средней $(3,41-6,23 \%)$. По гумусонакоплению в верхнем полуметровом слое буроземы темные иллювиально-гумусовые $(309,7 \mathrm{~T} /$ га) значительно опережают буроземы типичные $(167,4 \mathrm{~T} /$ га) и буроземы темные $(213,54 \mathrm{т} / г а)$ [10].

Помимо этого, состояние и состав растительности оказывают прямое влияние на состав образующихся продуктов разложения и гумификации, состав водорастворимой фракции органического вещества в подстилке и почве [13], обусловливая динамику внутрипрофильной дифференциации почвенного гумуса.

Групповой и фракционный состав гумуса буроземов острова Русский (числитель - \% веса почвы, знаменатель - \% $\mathrm{C}_{\text {общ }}$ ) /

Group and fractional humus composition of burozems on Russky

Island (numerator - \% of soil weight, denominator - \% of $\mathrm{C}_{\text {total }}$ )

\begin{tabular}{|c|c|c|c|c|c|c|c|c|c|c|c|c|}
\hline \multirow{2}{*}{$\begin{array}{c}\text { Глубина } \\
\text { горизонта, см } \\
\text { Horizon } \\
\text { depth, cm }\end{array}$} & \multirow{2}{*}{$\mid \begin{array}{c}\mathrm{C}_{\text {общ }} \\
\mathrm{C}_{\text {total }} \text {, } \\
\%\end{array}$} & \multicolumn{4}{|c|}{$\begin{array}{c}\text { Гуминовые кислоты / } \\
\text { Humic acids }\end{array}$} & \multicolumn{5}{|c|}{$\begin{array}{c}\text { Фульвокислоты / } \\
\text { Fulvic acids }\end{array}$} & \multirow{2}{*}{$\begin{array}{l}\mathrm{HO}^{*} \\
\mathrm{NR}^{*}\end{array}$} & \multirow{2}{*}{$\begin{array}{l}\mathrm{C}_{\mathrm{rK}} / \mathrm{C}_{\mathrm{\phi K}} \\
\mathrm{C}_{\mathrm{HA}} / \mathrm{C}_{\mathrm{FA}}\end{array}$} \\
\hline & & 1 & 2 & 3 & $\sum$ & 1 & 2 & 3 & $\sum$ & 1a & & \\
\hline \multicolumn{13}{|c|}{ Бурозем типичный, разрез 27-02 / Typical burozem, vertical profile 27-02 } \\
\hline & \multirow{2}{*}{6,39} & 1,03 & $\underline{0,28}$ & $\underline{0,48}$ & $\underline{1,79}$ & $\underline{0,29}$ & $\underline{0,49}$ & $\underline{0,77}$ & $\underline{0,69}$ & 2,24 & $\underline{2,36}$ & \multirow{2}{*}{0,8} \\
\hline $0,5-$ & & 16,12 & 4,38 & 7,51 & 28,01 & $\overline{4,54}$ & 7,67 & 12,05 & $\overline{10,80}$ & $3 \overline{35,05}$ & $\overline{36,93}$ & \\
\hline & \multirow{2}{*}{1,16} & $\underline{0,12}$ & 0,02 & $\underline{0,06}$ & $\underline{0,20}$ & $\underline{0,26}$ & $\underline{0,11}$ & $\underline{0,15}$ & 0,17 & $\underline{0,69}$ & $\underline{0,27}$ & \multirow{2}{*}{0,29} \\
\hline $8(15)$ & & 10,34 & 1,72 & 5,12 & 17,24 & 22,40 & 9,48 & 12,93 & 14,66 & 59,48 & 23,28 & \\
\hline & \multirow{2}{*}{0,85} & $\underline{0,09}$ & 0,01 & $\underline{0,04}$ & $\underline{0,14}$ & $\underline{0,20}$ & $\underline{0,06}$ & $\underline{0,12}$ & $\underline{0,13}$ & $\underline{0,51}$ & $\underline{0,20}$ & \multirow{2}{*}{0,27} \\
\hline & & 10,58 & 1,18 & 4,71 & 16,47 & 23,52 & 7,06 & 14,12 & 15,29 & 60,00 & 23,53 & \\
\hline \multicolumn{13}{|c|}{ Бурозем темный, разрез 21-02 / Dark burozem, vertical profile 21-02 } \\
\hline & \multirow{2}{*}{8,15} & $\underline{1,32}$ & $\underline{0,69}$ & $\underline{0,6}$ & $\underline{2,61}$ & $\underline{0,4}$ & $\underline{0,33}$ & $\underline{1,16}$ & $\underline{0,64}$ & $\underline{2,53}$ & $\underline{3,01}$ & \multirow{2}{*}{1,03} \\
\hline $2,5-13(27)$ & & 16,20 & 8,47 & 7,36 & 32,02 & 4,91 & 4,05 & 14,23 & 7,85 & 31,04 & 36,93 & \\
\hline & \multirow[b]{2}{*}{1,97} & $\underline{0,41}$ & $\underline{0,09}$ & $\underline{0,06}$ & $\underline{0,56}$ & $\underline{0,23}$ & $\underline{0,06}$ & $\underline{0,19}$ & $\underline{0,24}$ & 0,72 & 0,69 & \multirow{2}{*}{0,78} \\
\hline $13(27)-38$ & & 20,80 & 4,57 & 3,05 & 28,43 & 11,68 & 3,05 & 9,64 & 12,18 & 36,55 & 35,03 & \\
\hline $\mathrm{BM}$ & \multirow{2}{*}{0,8} & 0,18 & 0,01 & 0,03 & 0,22 & 0,12 & 0,04 & $\underline{0,11}$ & 0,13 & 0,40 & 0,18 & \multirow{2}{*}{0,55} \\
\hline & & 22,50 & 1,25 & 3,75 & 27,50 & $\overline{15,00}$ & $\overline{5,00}$ & $\overline{13,75}$ & $\overline{16,50}$ & $\overline{50,00}$ & 22,50 & \\
\hline \multirow{2}{*}{\multicolumn{13}{|c|}{$\begin{array}{c}\text { Бурозем темный иллювиально-гумусовый, разрез 23-02 } \\
\text { Dark humus-illuvial burozem, vertical profile 23-02 }\end{array}$}} \\
\hline & & & & & & & & & & & & \\
\hline $\mathrm{AU}$ & \multirow{2}{*}{8,65} & $\underline{1,29}$ & $\underline{0,79}$ & $\underline{0,8}$ & $\underline{2,88}$ & $\underline{0,3}$ & $\underline{0,53}$ & 1,09 & $\underline{0,58}$ & $\underline{2,5}$ & $\underline{3,27}$ & \multirow{2}{*}{1,15} \\
\hline & & $\overline{14,9}$ & 9,13 & $\overline{9,2}$ & 33,29 & 3,47 & 6,10 & $\overline{12,6}$ & 6,7 & 28,9 & 37,80 & \\
\hline AUBMhi & \multirow{2}{*}{3,61} & $\underline{0,66}$ & $\underline{0,22}$ & $\underline{0,32}$ & $\underline{1,2}$ & $\underline{0,23}$ & $\underline{0,26}$ & $\underline{0,29}$ & $\underline{0,32}$ & $\underline{1,10}$ & $\underline{1,31}$ & \multirow{2}{*}{1,09} \\
\hline $16-25(27)$ & & $\overline{18,28}$ & $\overline{6,09}$ & $\overline{8,86}$ & 33,24 & $\overline{6,37}$ & 7,20 & 8,03 & 8,86 & 30,47 & 36,9 & \\
\hline & \multirow{2}{*}{2,37} & $\underline{0,38}$ & 0,08 & $\underline{0,09}$ & $\underline{0,55}$ & $\underline{0,16}$ & $\underline{0,07}$ & $\underline{0,21}$ & $\underline{0,28}$ & $\underline{0,72}$ & 1,10 & \multirow{2}{*}{0,76} \\
\hline $25(27)-53$ & & 16,03 & 3,38 & 3,79 & 23,21 & 6,75 & 2,95 & 8,86 & 11,81 & 30,38 & 46,41 & \\
\hline
\end{tabular}

* Негидролизуемый остаток / Nonhydrolyzed residue.

Буроземы, формирующиеся под дубовыми лесами с очень слабо развитым травяно-кустарниковым ярусом, характеризуются гуматно-фульватным типом гумуса, отношение $\mathrm{C}_{\text {гк }} / \mathrm{C}_{\text {фк }}$ составляет 0,8 . С глубиной в составе гумуса резко возрастает доля фульвокислот за счет наиболее агрессивной и подвижной фракции ФК-1а и тип гумуса изменяется на очень фульватный. 
В групповом составе гумуса буроземов темных под изреженными дубняками со сравнительно хорошо развитым травяно-кустарниковым ярусом и буроземов темных иллювиально-гумусовых под изреженными дубняками с хорошо развитым травяно-кустарниковым ярусом явно преобладают гуминовые кислоты; соотношение $\mathrm{C}_{\text {гк }} / \mathrm{C}_{\text {фк }}$ увеличивается до 1,03-1,15 соответственно, а тип гумуса изменяется на фульватно-гуматный.

Характерной особенностью буроземов темных иллювиально-гумусовых, отличающей их от других буроземов острова, является фульватно-гуматный тип гумуса не только в верхнем гумусово-аккумулятивном $\left(\mathrm{C}_{\text {гк }} / \mathrm{C}_{\phi к}-1,15\right)$, но и в иллювиально-гумусовом горизонтах $\left(\mathrm{C}_{\text {гк }} / \mathrm{C}_{\phi к}-1,08\right)$. Данные фракционного состава гумуса этих буроземов свидетельствуют о более высоком по сравнению с другими буроземами содержании гуминовых кислот и их отдельных фракций в пределах всего почвенного профиля.

В группе гуминовых кислот всех исследуемых буроземов преобладает фракция, связанная с подвижными полуторными оксидами (ГК-1).

Распределение фракции ГК-1 по профилю буроземов темных и буроземов темных иллювиально-гумусовых свидетельствует об усилении подвижности гумуса и отражает развитие в этих почвах иллювиально-гумусового процесса почвообразования. Максимум относительного содержания этой фракции в буроземах темных иллювиально-гумусовых приурочен к горизонту AUBMhi $\left(18,28 \% \mathrm{C}_{\text {обш }}\right)$. В буроземах темных отмечается рост относительного содержания этой фракции от гумусово-аккумулятивного горизонта к горизонту ВМС. В буроземах типичных содержание фракции ГК-1 постепенно убывает от гумусово-аккумулятивного горизонта вниз по профилю, что в целом типично для гумуса этого типа буроземов.

Определяющими показателями качественного состава гумуса островных буроземов являются уровень содержания фракции черных гуминовых кислот (ЧГК) и характер ее профильного распределения.

Буроземы под изреженными дубняками с хорошо развитым травяно-кустарниковым ярусом выделяются как абсолютно, так и относительно более высоким содержанием фракции ЧГК (9,13-6,09-3,38\% от С обш $)$ по всей почвенной толще. Значительное количество фракции ЧГК и обусловливает преимущественно более глубокую и темную окраску их гумусового профиля по сравнению с другими буроземами острова.

В буроземах, формирующихся под дубовыми лесами с очень слабо развитым травяно-кустарниковым ярусом, почти все гуматы кальция аккумулируются в верхнем горизонте $\left(4,38 \% \mathrm{C}_{\text {общ }}\right)$; вниз по профилю содержание их падает до $1,18 \% \mathrm{C}_{\text {общ }}$ в горизонте $\mathrm{BC}$.

Распределение фракции ЧГК по профилю буроземов темных равномерно убывающее, основная часть $\left(8,47 \% \mathrm{C}_{\text {общ }}\right)$ этой фракции осаждается в гумусово-аккумулятивном горизонте почв, но и в горизонте AUBM ее содержится достаточно высокое количество $\left(4,57 \% \mathrm{C}_{\text {общ }}\right)$. 
В закономерностях распределения группы гуминовых кислот фракции ГК-3 существенных различий в сравниваемом ряду буроземов не обнаружено. Содержание этой фракции во всех буроземах острова значительно (7,36-9,2\% от $\mathrm{C}_{\text {обш }}$ ), а распределение по профилю - постепенно убывающее.

В составе фульвокислот верхнего гумусово-аккумулятивного горизонта во всех буроземах острова преобладает фракция кислот, связанных с кальцием (ФК-Са). Наиболее высокие показатели абсолютного содержания этой фракции отмечают в профиле буроземов темных иллювиально-гумусовых. Эти же буроземы выделяются и более высокими значениями содержания ЧГК+ФК-Са. Доля ФК-Са понижается по профилю с глубиной. В нижних минеральных горизонтах буроземов типичных на первое место по накоплению выходит фракция агрессивных фульвокислот ФК-1a (22,5-23,52\% $\mathrm{C}_{\text {обш }}$ ), а в буроземах темных и буроземах темных иллювиально-гумусовых - фракция фульвокислот, прочно связанных с глинистыми минералами, $-3 Ф К ~\left(8,86-16,50 \% \mathrm{C}_{\text {общ }}\right)$ при значительном накоплении фракции $2 \Phi К$ $\left(8,44-13,75 \% \mathrm{C}_{\text {обш }}\right)$.

\section{Заключение}

Результаты проведенных нами исследований почвенно-растительного покрова острова Русский свидетельствуют о взаимосвязи между динамикой содержания и состава гумуса в буроземах и характером антропогенной трансформации растительности, под которой они формируются.

В условиях активного геохимического воздействия моря на процессы почвообразования антропогенная деградация лесной растительности острова сопровождается изменением направленности процессов гумусообразования в буроземах в сторону усиления гуматности их гумуса. От буроземов дубовых лесов с очень слабо развитым травяно-кустарниковым ярусом к буроземам изреженных дубовых лесов с хорошо развитым травяно-кустарниковым ярусом (преимущественно из лещины) в составе гумуса заметно возрастает доля гуминовых кислот, а тип гумуса изменяется с гуматно-фульватного на фульватно-гуматный.

Особенности морфологической дифференциации гумусового профиля приокеанических буроземов обусловлены различиями содержания и характера внутрипрофильного распределения фракций БГК, ЧГК, ЧГК+ФК-Са. В ряду буроземы типичные $\rightarrow$ буроземы темные $\rightarrow$ буроземы темные иллювиально-гумусовые по всему почвенному профилю значительно возрастает доля черных гуминовых кислот, ЧГК+ФК-Са и нарастает подвижность их гумуса (увеличивается содержание БГК). Динамика внутрипрофильной дифференциации гумусовых кислот в исследуемых буроземах определяет различную интенсивность развития в них аккумулятивно-гумусового и иллювиально-гумусового процессов почвообразования и предопределяет формирование их морфологического разнообразия. 


\section{Литература}

1. Добровольский Г.В., Урусевская И.С. География почв. М. : Изд-во Моск. ун-та : Наука, 2006. $458 \mathrm{c}$.

2. Пшеничников Б.Ф., Пшеничникова Н.Ф. Геохимическое воздействие Тихого океана на почвы юга Дальнего Востока // Почвоведение: история, социология, методология. М. : Наука, 2005. С. 291-295.

3. Орфанитский Ю.А. Основы лесного почвоведения. М. : Колос, 1982.88 с.

4. Южная часть Дальнего Востока. Природные условия и естественные ресурсы СССР / отв. ред. В.В. Никольская, А.С. Хоментовский. М. : Наука, 1969. 422 с.

5. Урусов В.М., Чипизубова М.Н. О голоцен-современных сменах ландшафтов окрестностей г. Владивостока // Исследование и конструирование ландшафтов Дальнего Востока и Сибири. Владивосток : ДВО РАН, 1993. Вып. 1. С. 155-168.

6. Недолужко В.А., Денисов Н.И. Флора сосудистых растений острова Русский (залив Петра Великого в Японском море). Владивосток : Дальнаука, 2001. 98 с.

7. Шишов Л.Л., Лебедева И.И., Герасимова М.И. Классификация и диагностика почв России. Смоленск : Ойкумена, 2004. 342 с.

8. Латышева Л.А. Морфологическое разнообразие буроземов прибрежно-островной зоны юга Приморья // Вестник КрасГау. 2008. № 4. С. 45-50.

9. Пшеничников Б.Ф., Пшеничникова Н.Ф., Латышева Л.А. Антропогенная динамика морфологического строения и лесорастительных свойств буроземов острова Русский // Вестник КрасГау. 2010. № 12. С. 24-28.

10. Латышева Л.А. Антропогенная динамика гумусного состояния буроземов островов залива Петра Великого // Почвы России: Современное состояние, перспективы изучения и использования: материалы докл. VI Всерос. съезда общ-ва почв. им. В.В. Докучаева (Петрозаводск-Москва, 13-18 авг., 2012 г.). Петрозаводск ; Москва, 2012. Кн. II. C. 179-180.

11. Sauer T.J., Cambardella C.A., Meek D.W. Spatial variation of soil properties to vegetation changes // Plant and soil. 2006. Vol. 280. P. 1-5.

12. Dijkstra F.A., Breemen N.V., Jongmans A.G., Davies G.R., Likens G.E. Calcium weather in forested soils and effect of different tree spacies // Biogeochemistry. 2003. Vol. 62. P. 253275.

13. A Quideau S.A, Chadvwick O.A., Benesi A., Graham R.C., Anderson M.A. A direct link between forest vegetation type and soil organic matter composition // Geoderma. 2001. Vol. 104. № 1. P. 41-60.

Поступила в редакцию 25.11.2013 2.; повторно 28.12.2013 2.; принята 15.02.2014 г.

Латышева Лариса Алексеевна - н.с. лаборатории биогеографии и экологии Тихоокеанского института географии ДВО РАН (г. Владивосток, Россия).

E-mail: 1.a.lat@mail.ru 
Tomsk State University Journal of Biology. 2014. № 2 (26). P. 23-32

doi: $10.17223 / 19988591 / 26 / 2$

Larisa A. Latysheva

Laboratory of Biogeography and Ecology, Pacific Institute of Geography, Far Eastern Branch of the Russian Academy of Sciences, Vladivostok, Primorskii Krai, Russian Federation.

E-mail: 1.a.lat@mail.ru

\section{Influence of forest vegetation anthropogenic transformation on dynamics of humus content and composition in burozems of the island territory in the southern part of Primorskii Krai (Russia)}

The dynamics of humus content and humus composition in burozems of Russky Island, formed under the vegetation community of different stages of anthropogenic transformation, is considered.

Progressive anthropogenic degradation of Island vegetation and active geochemical influence of the sea on their soil cover, condition humus-formation and humusaccumulation processes in the burozems and create preconditions for developing humus-illuvial pedogenesis. It manifests itself in the dynamics of profile differentiation of humus content, its group and fractional composition, type of humus and determines morphological diversity.

The structure of the soil cover of Russky Island includes typical burozems, dark burozems and dark humus-illuvial burozems. Typical burozems are spread under oak and oak-lime forests with undereveloped grass and shrub layers. Dark burozems are formed under light oak forest with more developed grass and shrubs. Dark humusilluvial burozems are found under light oak forests with very developed grass and shrub layers. Investigated burozems differ considerably in humus contents, humus fractional composition and mobility level of their certain fractions. We found out that typical burozems are characterized by much lower humus content on all their profile, by humus composition of humate-fulvate type and the accumulative type of its profile distribution. Humic acids dominate in humus composition of dark burozems and dark humus-illuvial burozems in humus-accumulative horizon and humate-fulvate type of humus-formation is replaced by the fulvate-humate type. One of the typical features of humus composition of dark humus-illuvial burozems is the fulvate-humate type of humus both in the humusaccumulative horizon and in the humus-illuvial horizon. Profile distribution of humus of this burozems is defined by the combination of the humus-accumulative and humusilluvial processes of pedogenesis. Morphological differentiation of humus profile of burozems of the island is specific profile distribution of brown humic acids, black humic acids and black humic acids combined with fulvic acids.

The content of black humic acids, black humic acids combined with fulvic acids in humus composition of investigated burozems and humus mobility (content of ГК1) increases considerably from burozems found under oak and oak-lime forests with underdeveloped grass and shrub layers to burozems, found under light oak forests with very developed grass and shrub layers. This conditions different intensity of development of humus-formation and humus-accumulation pedogenesis processes and predetermines formation of their morphological diversity.

The article contains 1 table, 13 ref.

Key words: southern part of Primorskii Krai; anthropogenic degradation vegetation; dynamics; humus content; humus composition. 


\section{References}

1. Dobrovolsky GV, Urusevskaya IS. Geografiya pochv [Geography of soils]. Moscow: Moscow University press, Nauka; 2006. 458 p. In Russian

2. Pshenichnikov BF, Pshenichnikova NF. Geokhimicheskoe vozdeystvie Tikhogo okeana na pochvy yuga Dal'nego Vostoka [Geochemical influence of the Pacific Ocean on soils of the Far East]. Pochvovedenie: istoriya, sotsiologiya, metodologiya [In: Soil science: history, sociology, methodology]. Moskow: Nauka; 2005. p. 291-296. In Russian

3. Orphanitsky YA. Osnovy lesnogo pochvovedeniya [Foundations of forest pedology]. Moskow: Kolos; 1982. 88 p. In Russian

4. Yuzhnaya chast' Dal'nego Vostoka. Prirodnye usloviya i estestvennye resursy SSSR [South part of the Far East. Natural condition and nature resources of the USSR]. Nikol'skaya VV, Khomentovskiy AS, editors. Moskow: Nauka; 1969. 422 p. In Russian

5. Urusov VM, Chipizubova MN. O golotsen-sovremennykh smenakh landshaftov okrestnostey g. Vladivostoka [On holocene-contemporary changes of landscapes of Vladivostok surroundings]. Issledovanie $i$ konstruirovanie landshaftov Dal'nego Vostoka i Sibiri [In: Investigation and constructing of landscapes of the Russian Far East and Siberia]. Vladivostok: Pacific Institute of Geography, Far East branch of the Russian Academy of Sciences; 1993. Vol. 1. p. 155-168. In Russian

6. Nedoluzhko VA, Denisav NI. Flora sosudistykh rasteniy ostrova Russkiy (zaliv Petra Velikogo v Yaponskom more) [Vascular flora of Russky Island (the Peter the Great Gulf, the Sea of Japan)]. Vladivostok: Dalnauka; 2001. 98 p. In Russian

7. Klassifikatsiya i diagnostika pochv Rossii [Classification and Diagnostics of Soils of Russia]. Shishov LL, Tonkonogov VD, Lebedeva II, Gerasimova MI, editors. Smolensk: Okuimena; 2004. 342 p. In Russian

8. Latysheva LA. Morphological diversity of burozems of the maritime-island zone in the south of Primorskii Krai. Vestnik KrasGAU. 2008;4:45-50. In Russian

9. Pshenichnikov BF, Pshenichnikova NF, Latysheva LA. Antropogennous dynamics of burozem morphological structure and properties for forest growing on Russky island. Vestnik KrasGAU. 2010;12:24-28. In Russian

10. Latysheva LA. Antropogenous dynamics of burozems humus state on the islands of the Peter the Great Gulf. Proceedings of the VI congress of V.V. Dokuchaev Soil Society. Soils of Russia: Contemporary state, prospects of studying and using. [Electronic resource]. Petrozavodsk: Karelian scientific centre RAS; 2012. Vol. 2. p. 179-180. In Russian

11. Sauer TJ, Cambardella CA, Meek DW. Spatial variation of soil properties relating to vegetation changes. Plant and Soil. 2006;280:1-5. doi: 10.1007/s11104-005-1545-8.

12. Dijkstra FA, Breemen NV, Jongmans AG, Davies GR, Likens GE. Calcium weathering in forested soils and the effect of different tree species. Biogeochemistry. 2003;62:253-275. doi: 10.1023/A:1021132132199

13. A Quideau SA, Chadvwick OA, Benesi A, Graham RC, Anderson MA. A direct link between forest vegetation type and soil organic matter composition. Geoderma. 2001;104(1):41-60. doi: http://dx.doi.org/10.1016/S0016-7061(01)00055-6

Received 25 November 2013; Reviced 28 December 2013; Accepted 15 February 2014 